\title{
DEMOCRACIA Y OBEDIENCIA AL DERECHO: EL ARGUMENTO DE CARLOS NINO
}

\author{
RiCARDO CARACCIOLO \\ Universidad Nacional de Córdoba
}

\section{Resumen}

Este trabajo se propone, como un paso final, el examen del argumento de Carlos Nino a favor de la existencia de una obligación moral de obedecer al derecho producido por un gobierno democrático. Este argumento vendría a mostrar además que la democracia es la única forma de gobierno moralmente legítima. En la idea de Nino ambas cuestiones son equivalentes y una respuesta positiva es considerada necesaria para determinar la posibilidad de justificación de las decisiones de los jueces. La tesis en cuestión se apoya en una compleja concepción acerca de dimensión justificatoria del derecho y su conexión con la moral, como una condición necesaria. Por ello, se revisa las nociones de las que depende esa propuesta de Nino, especialmente las ideas de razón para la acción, justificación, principio moral y norma jurídica y se formula un interrogante acerca del éxito del argumento, si se acepta esa concepción general.

PALABRAS CLAVE: Razón para la acción; Justificación normativa; Moral; Democracia; Obediencia al derecho.

\begin{abstract}
This paper attempts to examine Carlos Nino's argument supporting the existence of a moral obligation to obey the law produced by a democratic government. This argument also goes on to show that democracy is the only morally legitimate form of government. In Nino's conception, both issues are equivalent, and a positive response is considered necessary to determine the possibility to justify judges' decisions. The thesis in question rests on a complex conception regarding the law's justificatory dimension, and its connection with morality as a necessary condition. This is why the notions upon which Nino's proposal rests are examined, above all the ideas of reason for action, justification, moral principle and legal norm. If we accept this general conception, then we should ask about the success of the argument.
\end{abstract}

KEY WORDS: Reason for Action; Normative Justification; Morality; Democracy; Obeying the Law.

\section{Introducción}

1. Es un genuino honor participar con algunas ideas en un homenaje a la memoria de Carlos Nino, un intelectual digno de admiración y un excelente amigo de aquellos que tuvimos la suerte de conocerlo. Siempre 
vale la pena advertir, y esta es una oportunidad más, la irreparable pérdida que significó su temprana muerte Sin duda, hubiera participado como siempre lo hacía, con entusiasmo y honestidad a toda prueba, en cualquier debate acerca de sus propuestas como el que se propone ahora. Y sin duda también todos hubiéramos aprendido algo novedoso de su intervención con relación a algún punto especialmente complejo de la filosofía práctica. Pero su ausencia material no puede impedir de manera alguna su condición de esencial compañero de ruta intelectual, alguien de cuyo pensamiento no es posible prescindir a la hora de procurar respuestas a interrogantes básicos en los ámbitos de la ética, del derecho y la política, los que para Nino están inexorablemente asociados. Uno de ellos es sin duda el siguiente: ¿existe una obligación general de obedecer al derecho?, el cual, por supuesto, es el reverso del que se refiere a la autoridad del derecho, es decir, a la posibilidad de una autoridad legítima.

2. Me propongo como objetivo final en este artículo revisar una original respuesta de Nino a ese problema. Si esa obligación existe solo puede ser de carácter moral. En última instancia solo si las normas son válidas, i.e. realmente obligatorias, y solo pueden tener esa condición si provienen de un gobierno cuya autoridad es legítima. Es decir, si se le puede adjudicar una suerte de autoridad moral. Solo los gobiernos democráticos -sostiene Nino- son (o pueden ser) legítimos en ese sentido. Solo existe, entonces, semejante obligación con respecto al derecho de una sociedad democrática. De manera que su argumento asocia una respuesta limitada con respecto a la obligación general de obediencia -solo las autoridades democráticas son legítimas- con la posibilidad de justificar moralmente la democracia como forma de gobierno. ${ }^{1}$ De lo cual se sigue-aunque Nino no lo haya indicado- que si no existe esa posibilidad, no hay manera de justificar aquella obligación general. Y recíprocamente. ${ }^{2}$ Un argumento que Nino presentó en forma pormenorizada en un temprano trabajo aparecido en Análisis Filosófico ${ }^{3}$. Se trata de un complejo argumento, que requiere para su análisis la presentación del itinerario que conduce a ese resultado a través de los presupuestos asumidos para sostener semejante tesis. Por consiguiente, mi objetivo aquí es continuar ese debate.

\footnotetext{
${ }^{1}$ Otra respuesta se sustenta en la idea de "razón auxiliar". No será examinada aquí.

${ }^{2}$ La inversa también vale, como lo indica expresamente Nino en el mismo artículo: si no se puede justificar la legitimidad moral de algún gobierno -en contra del anarquismo- no es posible defender la existencia de una obligación moral de obedecer al derecho (Nino, 1986a, pp. 66-67).

${ }^{3}$ Nino (1986a), con las objeciones de Farrell (1986) y Rodríguez Larreta (1986) y las respuestas de Nino (1986b) en el mismo número.
} 


\section{Conceptos de derecho}

1. Nino sostuvo con insistencia una discusión permanente con aquellos a quienes identificó con el positivismo jurídico, es decir con la concepción que niega cualquier conexión conceptual del derecho con la moral y que, por lo tanto, solo están dispuestos a identificar los contenidos de un derecho existente mediante el recurso a la corroboración de circunstancias empíricas, verbigracia, actos legislativos o prácticas sociales de variada naturaleza, con prescindencia de juicios de valor. En contraposición, para el jusnaturalismo ello constituye un error: la noción de derecho - para los partidarios de semejante concepción- solo puede ser normativa porque versa acerca de lo que se debe hacer, de manera que la identificación de las normas genuinamente jurídicas, esto es, de las que son obligatorias, las que son válidas, no puede prescindir de una evaluación moral. ${ }^{4}$

2. Pero la oposición de Nino al positivismo no lo clasifica necesariamente de manera directa entre los jusnaturalistas, al menos, no entre los que defienden una tesis tan drástica. Ello es así porque la misma controversia, i.e., la discusión acerca de cuál es la noción correcta de derecho, implica un esencialismo conceptual, que Nino denuncia y rechaza explícitamente (Nino 2014, cap. 1; Nino 2013, p. 150 y ss., entre otros trabajos). Nada impide formular distintos conceptos de derecho, unos descriptivos y otros normativos, que pueden resultar fructíferos, útiles, o necesarios, para satisfacer distintas funciones en distintos contextos. Retomando la distinción de Hart entre punto de vista externo acerca del derecho, propio de un observador que no participa en la práctica jurídica, y el punto de vista interno, esto es, el que asumen sus aceptantes, los conceptos descriptivos vendrían a corresponder al punto de vista externo y los normativos al punto de vista interno. Es más, dice Nino, esta distinción se formula -como lo habría hecho Hart- como herramienta descriptiva: y no es posible realizarla, o es irrelevante, cuando se adopta el punto de vista de los aceptantes (Nino 2014, pp. 48 y ss.). Los conceptos normativos de derecho se dirigen a capturar su carácter obligatorio, su condición de conjunto de normas válidas o, si se quiere, de razones para la acción. Ello es así porque el punto de vista interno es el de aquellos, en especial los jueces, que intervienen en la práctica de usar el derecho para justificar acciones y decisiones. Y es aquí donde la tesis de Nino da un esencial paso adicional (que será revisado en lo que sigue): como no

${ }^{4}$ Otros conceptos de "validez" son posibles. No serán discutidos en este trabajo. 
es posible justificar acciones o decisiones, verbigracia, las decisiones judiciales, que afectan intereses de terceros, sin el recurso a consideraciones morales, la conexión necesaria entre derecho y moral es ineludible en la dimensión o contexto de la práctica de justificación (Nino 2014, pp. 61-63) aunque no resulte necesaria en la identificación del material jurídico (Nino 2013, p. 164). De nuevo, se sigue, aunque Nino no lo indique de esta manera, que si no existe semejante conexión, el derecho no puede ser obligatorio $\mathrm{y}$, por consiguiente, no sirve para justificar conductas o decisiones. No habría razón alguna para cumplir con el derecho. Se puede acordar con esta tesis central y, sin embargo, preguntarse si Nino tiene éxito en mostrar esa conexión en contra del positivismo. Parece que para continuar es preciso analizar aún más la propuesta de distinguir entre clases de conceptos.

3. Hay dos problemas aquí. En primer lugar hay que indicar que ambos tipos de conceptos no son -en su idea- totalmente independientes: Nino dice explícitamente que el punto de vista interno tiene prioridad lógica: al menos, porque -de acuerdo también con Hart- no es posible prescindir en cualquier descripción de un determinado derecho del dato según el cual su práctica incluye la existencia de aceptantes (Nino 2014, p. 51, pp. 54 y ss.). Es por ello que el concepto o conceptos normativos tendrían que considerarse prioritarios sobre cualquier concepto descriptivo. Esto es discutible. Con un concepto normativo de derecho, esto es, aquel que presenta como "derecho" un conjunto de normas válidas, se puede construir un modelo ideal que funcione como patrón de crítica moral de algún derecho empíricamente existente, es decir, de un derecho positivo que puede ser identificado mediante un concepto descriptivo. Esta es la alternativa del jusnaturalismo. Es por supuesto obvio que entendida de esta manera no hay relación de prioridad lógica alguna: el concepto normativo vendría a identificar como "derecho" un conjunto de normas o principios morales distinto que el identificado con algún concepto descriptivo construido con criterios empíricos. La coincidencia solo podría ser contingente. Tiene razón Nino cuando afirma que conceder un privilegio a una u otra de las alternativas conceptuales para el uso de la palabra "derecho" puede ser un síntoma de esencialismo. O, tal vez, una mera discusión verbal. Pero creo que esa no es la manera de comprender la importancia de la distinción en su propuesta. Nino piensa que ambos tipos de conceptos están disponibles para capturar características distintas de un mismo "objeto", es decir, si se quiere, de un mismo material, i.e., las normas de lo que hay que considerar, de acuerdo a algún concepto descriptivo, un derecho positivo existente y no, necesariamente, un derecho 
ideal. Pero si esto es así, la prioridad parece que hay que concedérsela al concepto descriptivo en cuestión, porque este es el que permite identificarlo. Esto es, saber cuáles son los requerimientos de conducta que los aceptantes consideran "normas válidas". No habría derecho alguno, en este sentido de "derecho positivo", si no se satisface algún criterio empírico. Por lo tanto, tampoco habría "punto de vista interno" ni la correlativa práctica de uso de un concepto normativo con relación a algún derecho existente. Ahora bien, sea como sea, es verdad que el concepto normativo al que se dirige Nino se propone seleccionar las normas que deben ser cumplidas, las normas genuinas, esto es, las normas válidas. Los aceptantes de las normas de un derecho positivo son los usuarios de esa clase de conceptos.

4. Pero aquí aparece la segunda cuestión problemática para entender la propuesta de Nino: estos conceptos ison "normativos" porque son necesarios para expresar normas? Si fuera así, los correspondientes enunciados que los usen, por ejemplo "la Constitución C es válida" no podrían considerarse proposiciones, sino más bien normas o directivas encubiertas acerca de la Constitución C. Una manera de prescribir que $\mathrm{C}$ debe ser obedecida. De esta forma ha sido comprendida la idea de "validez", en el sentido normativo, por ejemplo por Carlos Alchourrón y Eugenio Bulygin, al elucidar la idea de enunciado interno (Alchourrón y Bulygin 1996). Entendidos de esta manera, no habría oposición con los conceptos descriptivos, porque los "normativos" vendrían a carecer de cualquier contenido cognoscitivo. No podrían servir, por lo tanto, para identificar entidades o propiedades en el mundo. ${ }^{5}$ Más bien, en alguna forma de entender el uso de un lenguaje prescriptivo, solo podrían servir para expresar actitudes de desaprobación o de rechazo. Parece que esta no es la opción elegida por Nino. Aunque no de manera demasiado precisa, dice que la "validez" de una norma -al igual que Kelsen- requiere ineludiblemente de otra norma:

Por lo tanto, estos conceptos normativos de derecho presuponen el empleo de normas o principios diferentes a los denotados por el mismo. Es por eso, y no porque denoten normas -como también lo hacen los conceptos descriptivos- que estos conceptos son calificados de "normativos “. Esta propiedad de ser debidos, que este concepto asigna

5 De acuerdo con Peacocke "un concepto es un modo de pensar algo, un objeto particular, o una propiedad, o una relación, o alguna otra entidad" (Peacocke, 1997, p. 74, traducción nuestra). No habría, en esa lectura, ninguna idea asociada con la expresión "validez". 
a los estándares denotados como jurídicos, es también aludido con la propiedad de "validez", entendida como fuerza obligatoria o vinculante (Nino 2014, p. 41, las cursivas son nuestras).

5. Nino asume aquí -de acuerdo a este párrafo- un compromiso ontológico básico: existen propiedades normativas en el mundo, i.e. la propiedad "validez" y, por consiguiente, los enunciados que la predican de ciertos requerimientos de conducta, como las directivas jurídicas, tienen que ser consideradas genuinas proposiciones susceptibles de ser verdaderas o falsas. ${ }^{6}$ Pero se trata de una propiedad relacional: su existencia, en una norma $\mathrm{N}$, como lo indica expresamente, depende de la existencia de otras normas N1, N2,...Nn que justifiquen N. Uno puede suponer que esa relación de justificación es la que transmite la propiedad validez, así como la relación de deducción transmite la verdad entre proposiciones. ${ }^{7}$ Como la secuencia de normas no puede ser infinita, es preciso admitir -además- una noción no relacional de "validez": algunas normas tienen que considerarse absolutamente válidas: para Nino es claro que estas son las que integran la moral crítica u objetiva. Considero que este es, tal vez, el mejor argumento para sostener la unidad o no fragmentación del discurso práctico o normativo -tesis de la cual Nino fue un recurrente defensor-y la dependencia objetiva de las normas jurídicas con relación a la moral (Nino 2014, pp. 82 y ss.). Pero esto quiere decir que los aceptantes que usan un concepto normativo así entendido son los que adoptan ciertas actitudes cognitivas: creen que las normas jurídicas que aceptan son efectivamente válidas, que están dotadas de esa propiedad. Sin embargo, ello conduce a un resultado en cierto modo paradójico que, de nuevo, pone en cuestión la postulada prioridad del punto de vista interno. Porque solo desde el punto de vista externo podría evaluarse si semejantes creencias son falsas o verdaderas ${ }^{8}$, porque para ello hay que

${ }^{6}$ Nino dice expresamente, en alguna oportunidad, que los juicios de valor, que tendrían la misma naturaleza que lo que denomina "juicios normativos morales", son calificables como verdaderos o falsos (Nino 1981, p. 40). Ello aunque también distingue entre normas que son prescripciones y proposiciones acerca de normas. Una distinción difícil de mantener si las normas pueden ser verdaderas. No obstante, no voy a discutir aquí esta cuestión.

${ }^{7}$ Dice Nino: "La fuerza obligatoria de una norma jurídica es una noción normativa y hace referencia a una propiedad que puede ser transmitida de una norma a otra" (Nino 2014, p. 80).

8 Si se está dispuesto a admitir la tesis ontológica que implica — de acuerdo a este argumento- la adopción del punto de vista interno. Pero ello muestra que la distinción entre puntos de vistas es relativa: nada impide que — desde el punto de vista externo- 
abandonar el punto de vista interno, esto es, la condición de aceptante. Este resultado, como se verá, es importante a la hora de pronunciarse sobre el argumento de Nino con relación a la validez del derecho.

\section{Justificación}

1. En términos generales, por justificar se entiende la actividad de suministrar razones a favor, por ejemplo, de una creencia o de una decisión o de una acción o de una norma. Mostrar-como ya se dijo-que una norma es válida requiere mostrar que se justifica en otras normas. De acuerdo a esta idea general, parece que los jueces efectivamente justifican en el derecho sus decisiones. Esta es la dimensión justificatoria de la práctica del derecho. Uno podría decir que, si se acuerda que para avalar su sentencia un juez invoca normas generales cuya pertenencia al derecho no se discute y efectivamente la norma particular se sigue lógicamente de esas premisas, su decisión se justifica en el derecho, con prescindencia de su evaluación moral (Alchourrón y Bulygin 1971, cap. VIII, pp. 153 y ss.). Lo cual vendría a significar que el derecho constituye un dominio de razones. En todo caso, esta parece constituir la idea estándar de justificación jurídica, incorporada en esa práctica. Nino desacuerda en forma total con esta idea, otro frente de oposición con lo que considera un eslogan del positivismo. Su tesis es que no puede haber justificación de acciones al margen de la moral.

2. Es importante determinar el alcance de su argumento para arribar a esa conclusión. No se trata de que, evidentemente, para cada acción o decisión posible, siempre será posible su evaluación moral, a la par de su evaluación jurídica. Esto es, lo que aquella idea estándar podría admitir es que pueden existir decisiones de los jueces que se justifican en un cierto derecho, pero que son inmorales, i.e. que transgreden un deber moral. Lo que resulta de la concepción de Nino es más fuerte: en tal caso, no existe justificación alguna. O lo que significa lo mismo, no puede haber justificación de acciones inmorales, en ningún sentido. Pero, esta idea no se sigue solo de su propuesta acerca de la justificación de normas, es decir, de su afirmación de que predicar la propiedad "validez" de directivas

un observador se pronuncie acerca de la presencia o ausencia de la propiedad "validez" con relación a un cierto derecho. El mismo Hart sostuvo que la pregunta acerca de la existencia de una obligación moral de obedecer al derecho se tiene que formular desde el punto de vista externo ( $c f$. Hart 1991, p. 104), es decir, desde afuera de la regla de reconocimiento. 
jurídicas requiere necesariamente el recurso a otras normas. Uno podría suponer, cualesquiera sean las dificultades para mostrarlo, que las normas últimas, en la cadena de justificación, son también jurídicas, i.e. la constitución de un cierto sistema jurídico. Nino rechaza también expresamente esta alternativa, por ejemplo, frente a Kelsen (Nino 2014, pp. 78-80), pero parece que no puede mantener ese rechazo -sin plus petitio- aduciendo que siempre es posible la evaluación moral de semejante constitución o que las normas últimas necesariamente tienen que tener carácter moral.

3. Más bien, el argumento básico de Nino aquí -al menos como lo entiendo- consiste en negar que el ámbito jurídico pueda constituir un dominio autónomo de deberes, i.e. de razones para la acción (Nino 1984, Nino 2013, p. 156). Es decir, en negar lo que podría denominarse "internalismo jurídico" de las razones. Veremos más adelante porque ello es así. Por lo tanto, se sigue que no podría haber una versión relativista de la idea de justificación: una que acuerde que una cierta acción o decisión puede justificarse en un dominio jurídico pero no en un dominio moral o viceversa, a la vez que se sostenga que ambos dominios son inconmensurables. Pero parece importante indicar que esa negativa no se sigue únicamente del objetivismo moral o de la idea de la existencia de una moral objetivamente correcta, una concepción que, sin duda alguna, es el trasfondo de la filosofía práctica de Nino. Una noción relativista de justificación no implica necesariamente una versión relativista de la moral. ${ }^{9}$

4. En contraposición, como es claro, Nino sostiene lo que actualmente se denomina "internalismo" de la moral, i.e., la tesis según la cual existen en forma autónoma deberes o razones morales, lo que vendría a explicar el carácter último de cualquier justificación moral. ${ }^{10}$

${ }^{9}$ Así, por ejemplo, Michael Zimmerman, un teórico sin duda comprometido con una clase de objetivismo moral, al presentar el conflicto eventual entre diversos puntos de vista que podrían conducir a un deber o a una razón, dice: "Por mi parte, sin embargo, no tengo comprensión alguna de ningún 'debe' trascendente. No logro entender cómo podría ser que diversos puntos de vista, morales y no morales, sean mutuamente conmensurables" (Zimmerman 1996, pp. 2-3, traducción nuestra). Ello es así porque para elegir la primacía de algunos de los dominios o puntos de vista normativos en conflicto, sería necesario postular un implausible "ought" trascendente a todos los dominios. Voy a retornar sobre esta cuestión más adelante.

10 Sin embargo, habría que indicar que se trata de dos cuestiones distintas: una se refiere a lo que hay considerar un dominio de razones, y la otra, a la eventual 
El recurso a la moral tiene que clausurar las controversias prácticas. Nino acepta sin demasiada discusión esta tesis que, supongo, consideraba evidente. Pero, de nuevo, esta no se sigue del objetivismo moral: así, por ejemplo, David Brink, un indiscutible realista moral, defiende una concepción según la cual la moral no suministra en forma independiente razones para la acción. Por consiguiente, la justificación moral no podría considerarse última o final (Brink 1994, cap. 3). ${ }^{11}$ Pero, en cualquier caso, si se acepta la propuesta de Nino, ninguna decisión judicial podría justificarse, si no mantiene una específica relación objetiva con algún principio moral.

5. Por consiguiente, si los aceptantes, en especial los jueces, son aquellos dispuestos a justificar sus decisiones, entonces tienen que admitir que sus sentencias se relacionan de esa manera con algún principio moral. Es notorio que gran parte de su argumento en favor de la conexión justificatoria del derecho con la moral recurre a la presentación de una cierta descripción de la práctica del discurso judicial. ${ }^{12}$ Sin embargo, esto puede conducir a algunos equívocos. Nino admite que hay una idea-que

jerarquía entre dominios, lo que supone que son conmensurables. Ello es así porque el mismo Nino supone que existe un ámbito de razones prudenciales, que, por definición, no son morales, aunque estas últimas superen en cualquier justificación a cualquier razón prudencial (Nino 2014, pp. 83 y ss., también Bayón 1991, especialmente cap. 5). Pero ello implica que, para cualquier acción A de un cierto individuo I puede haber una justificación, aunque derrotable, de carácter prudencial. Lo que es importante en el supuesto que la acción A se considere moralmente indiferente. Pero esta no parece ser su idea con relación al derecho según la cual no existen razones "jurídicas" autónomas. Por consiguiente, no puede existir “justificación jurídica”, y el uso de esta expresión es solo una manera de hablar.

${ }^{11}$ Como es notorio, también existe la secular controversia acerca de la posibilidad de justificar racionalmente el dominio moral, frente al escepticismo o al relativismo. Los argumentos tienen que recurrir así a un punto de vista arquimediano, a una idea de "razón" externa a la moral. Por ejemplo, la discusión de Williams (1993, especialmente cap. 2). No puedo incursionar en esa discusión. Me interesa indicar, más bien, que la hipótesis filosófica de Nino incluye una respuesta positiva a una cuestión abierta a la controversia.

12 No está claro que la reconstrucción de esa práctica justificatoria sea correcta, desde el punto de vista empírico. Como fue indicado anteriormente, la versión estándar de lo que significa "justificar" en el dominio jurídico, la que también podría invocar su apoyo en esa práctica, supone la independencia del derecho de la moral. No habría que confundir aquí el concepto de "justificación" que los jueces usan de hecho, con el que deberían usar. Nada impide aceptar el modelo ideal propuesto por Nino, y rechazar que se corresponda con la concepción actual de los jueces o de los juristas. Se trata de un punto importante, toda vez que Nino asocia toda su propuesta acerca de la relación entre moral y derecho, con el discurso moral que caracteriza a la Ilustración (Nino, 2014, pp. 52 -54, p. 62). 
considera en cierto modo superficial- de "justificación jurídica" que la identifica con la relación deductiva entre ciertas premisas normativas generales y el contenido de la norma particular elegida por un juez. Pero lo que le interesa elucidar es la idea de "justificación" en "el sentido de derivación de un enunciado válido, correcto, plausible o verdadero" (Nino 2007, p. 167 cursiva nuestra). Sin embargo, afirma también Nino:

Me parece claro que en el sentido relevante de justificación, no basta recurrir a una norma jurídica para justificar una decisión judicial, sino que, como sabemos desde Kelsen, esa norma debe ser asumida como válida. Del mismo modo que la justificación de una creencia no puede basarse en cualquier enunciado, sino en uno asumido como verdadero (Nino 2007, p. 167, la cursiva es nuestra).

6. Estas son distintas maneras no equivalentes de calificar a las premisas elegidas por un juez, porque "norma válida" o "enunciado verdadero", no es lo mismo que "norma asumida como válida" o "enunciado asumido como verdadero". Se puede decir que, efectivamente, y por definición de aceptante, las premisas que un juez selecciona son aquellas que considera válidas o verdaderas y con ello se apunta a un estado mental. Esto querría decir que las considera moralmente correctas ${ }^{13} y$, por consiguiente, que se justifica la decisión que está dispuesto a adoptar. Lo que conduce a lo que puede denominarse una versión subjetivista o pragmática de la justificación (una expresión que aparece con frecuencia en los escritos de Nino), que exige como requisito necesario y suficiente para considerar "justificada" una sentencia la condición de aceptante, i.e. la adopción del punto de vista interno. No habría justificación posible si el juez no es un aceptante. Es decir, si no cree que las premisas que elige son normas válidas. Esto es lo que resulta si solo se apela para construir la noción de "justificación" a la práctica del discurso jurídico ( $c f$. Nino 2014, p. 63 y ss.). ${ }^{14}$ Pero esta no puede ser la propuesta central que, con justicia, habría que adjudicar a Nino: para mantener la consistencia, lo que hay que defender es la conexión objetiva del derecho con la moral, esto es, las sentencias de los jueces se justifican objetivamente si, y solo si, las

13 Esto es similar a la noción de "aceptación por su contenido", a la que me refiero más adelante.

14 En esta dirección, Bayón es más explícito: "Por lo tanto, 'justificar', en sentido estricto, implicaría usar una norma que efectivamente se acepta, entendiendo que "aceptar una norma" no es sino adoptarla como razón justificativa para la acción" (Bayón 1991, p. 326). 
premisas de las que parten para alcanzar sus decisiones son, como lo enuncia en el párrafo citado arriba, objetivamente válidas o verdaderas. Para ello, es decir, para la existencia de la relación objetiva de justificación, parece que la actitud de aceptación no solo es insuficiente, sino también innecesaria. ${ }^{15}$ La noción de "justificación subjetiva" solo puede ser derivada y significa -como ya se dijo-que los jueces creen que las normas que adoptan para fundamentar sus decisiones tienen en su favor una garantía moral. Un positivista, tal vez refinado, podría aceptarla, sencillamente porque su uso solo requiere información acerca de creencias, i.e., información empírica, y negar a la vez coherentemente cualquier conexión objetiva necesaria del derecho y la moral, incluso en la dimensión justificatoria. Por ello, la concepción de Nino, opuesta al positivismo, requiere la versión objetivista de la noción de justificación.

\section{Razones para la acción}

1. La distinción "objetivo/subjetivo" en la idea de justificación no es más que la contrapartida del análisis de Nino del concepto de "razón para la acción". Recuérdese que una acción o una decisión solo se justifican si existen razones [concluyentes] en su favor. Pero hay que distinguir, de acuerdo con Nino, entre razones explicativas o subjetivas y razones justificatorias u objetivas para la acción. ${ }^{16}$ Las explicativas se identifican con los motivos de una acción y por ello habilitan dar cuenta de su ocurrencia empírica. Desde Hume, la versión estándar de una explicación semejante sostiene que la motivación necesaria vendría a requerir la presencia de un deseo. ${ }^{17}$ Pero Nino rechaza también la generalización de

15 Como, en la versión estándar atribuida al positivismo, ni la condición de pertenencia al derecho, de acuerdo a un concepto descriptivo, ni la relación de deducción, dependen de las creencias de los jueces, la relación de justificación debería también considerarse objetiva. Por lo tanto, la condición de aceptante sería también irrelevante para determinar si una sentencia se justifica o no se justifica. Este es un supuesto, como es claro, en la práctica de revisión de sentencias: no interesa saber si el juez en cuestión cree o no cree en la validez o en la verdad de sus premisas; sin perjuicio de que la hipótesis de la existencia de semejantes creencias pueda ser una herramienta para explicar las decisiones que adopta de hecho.

16 Cf. Nino (1984, p. 489). Se trata de un trabajo destinado a explorar sistemáticamente el concepto de "razón para la acción" y explicar por qué las normas jurídicas no pueden constituir razones justificatorias. La distinción "objetivo/subjetivo" no es tan clara en un trabajo anterior sobre la misma cuestión (Nino 1981). Cf. la crítica de Carlos Alchourrón a ese respecto en Alchourrón (1981).

17 No obstante, incluso en el plano de la explicación, Nino sostiene que no es, simplemente, el estado mental lo que cuenta: los deseos se pueden visualizar desde el 
esa exigencia y, de acuerdo con Thomas Nagel, Grice, Raz y otros, incluye a las creencias, en tanto estados mentales, que pueden contribuir a explicar los eventos denominados "acciones" (Nino 1984, pp. 489-491). No obstante, los hechos no pueden justificar acciones. Por lo tanto, no es posible identificar las razones justificatorias ni con deseos ni con creencias. Esto es realmente importante para el argumento de este trabajo: de acuerdo con Nino, hay que asumir la tesis correcta según la cual las creencias no pueden justificar acciones.

2. La distinción no excluye la existencia de relaciones lógicas entre ambos tipos de "razones": conjuntamente con Raz, Nino dice -en un todo de acuerdo con la postulada primacía del punto de vista interno- que el concepto de razón "explicativa" presupone el de razón "justificatoria": "En suma, una razón explicatoria es una creencia en una razón justificatoria" (Nino 1984, p. 491, traducción nuestra). Como ello es así, agrega Nino, parece que también debería rechazarse la conexión de los deseos con la idea de razón explicativa (ibíd.). Pero esta relación entre ambos tipos de razones requiere una aclaración. Podría decirse que:

(1) Existe una razón justificatoria u objetiva para un individuo A con relación a la acción $\mathrm{P}$ en un contexto $\mathrm{C}$ si, y solo si, A debe realizar $\mathrm{P}$ en $\mathrm{C}$.

(2) Existe una razón explicativa o subjetiva de la acción $\mathrm{P}$ del individuo A en $\mathrm{C}$, si y solo si, A cree que debe realizar $\mathrm{P}$ en $\mathrm{C}$.

Según (2) la existencia de una razón subjetiva equivale a la existencia de un estado mental, una cierta creencia, i.e. un dato empírico. Pero, para determinar el contenido de la creencia, hay que elucidar la noción de "razón justificatoria" u "objetiva". Este es el sentido en el cual, correctamente, enunciados del tipo (2) presuponen enunciados del tipo (1). Pero ello no vale con respecto a la verdad o falsedad de ambos enunciados, que son recíprocamente independientes. Por lo tanto, (2) puede ser verdadero y (1) falso, y viceversa. De la verdad de (2) nada se puede inferir acerca de (1) (en el mismo sentido, cf. Alchourrón 1981). ${ }^{18}$

punto de vista interno del individuo que actúa y esa perspectiva incluye en todo caso una evaluación del deseo (Nino 2014, pp. 49-50). También en el mismo sentido véase Quinn (1993).

18 Como es claro, tampoco esa dependencia conceptual clausura la posibilidad del escepticismo acerca de la existencia de razones objetivas, esto es, la tesis según la cual todos los enunciados del tipo (1) son falsos. 
3. Para determinar, entonces, cuáles son las condiciones de verdad de los enunciados del tipo (1), hay que identificar a las postuladas "razones objetivas" o "justificatorias". ${ }^{19}$ Nino, después de revisar varias alternativas, recurre para ello a una reconstrucción plausible de la idea de "razonamiento práctico". Por cierto, las razones justificatorias tienen que cumplir una función esencial en un razonamiento de esta clase. Así, en esa reconstrucción, se trata de una:

"inferencia lógica que nos permite evaluar o guiar la acción". Es evidente
que, en la medida en que nuestro propósito es elucidar el concepto de
razón justificatoria, estamos interesados por el último significado de
"razonamiento práctico", y también es evidente que un razonamiento
es apto para evaluar o guiar la acción solo cuando su conclusión es un
juicio normativo (Nino, 1984, pp. 492-493, cursiva y traducción nuestra).

4. Como ello es así, las premisas de semejantes razonamientos tienen que incluir también juicios normativos, esto es, juicios de "deber" para habilitar conclusiones normativas. De manera que las razones justificatorias, para formar parte de razonamientos prácticos lógicamente correctos, tienen que estar constituidas por requerimientos [o "principios"] normativos válidos, de los cuales pueden seguirse enunciados del tipo (1). Una razón explicativa o subjetiva no es otra cosa que una creencia en la validez de algún principio normativo ${ }^{20}$.Pero no cualquier requerimiento normativo es una razón normativa o justificatoria. Lo son solamente aquellos que satisfacen ciertas propiedades, en cierto modo, formales, todas las cuales son también adjudicadas a los principios morales. Por lo tanto, estos principios son -por definición- razones normativas o justificatorias. Tal vez, la propiedad esencial para la presente discusión es lo que Nino denomina autonomía. Esto quiere decir que un requerimiento normativo es una

19 Nino también distingue, siguiendo a Raz, entre razones "operativas" y "auxiliares": una razón operativa es una razón justificatoria "completa", esto, es suficiente para justificar una acción. No voy a ocuparme de esta distinción, porque no es necesario para el análisis que me propongo realizar aquí de su argumento acerca de la relación entre democracia y relevancia práctica del derecho. Nino, no obstante, como ya fue indicado, formula otra propuesta acerca de la función de los actos de promulgación de normas jurídicas que los asimila a "razones auxiliares", la que no voy a discutir aquí.

20 Para Nino, ello incluye también - como fue indicado- a los deseos, los que no podrían, por sí solos, constituir razones subjetivas: "un deseo, como acabamos de ver, expresa una adhesión a un juicio de deber ser, pero esa adhesión también puede describirse como una creencia en la validez de ese juicio" (Nino 1984, p. 493, traducción nuestra). 
razón normativa cuando su validez -en última instancia-no depende del hecho de que alguien lo haya formulado o aceptado, lo que se sigue de la postulada objetividad que hay que predicar de semejantes razones. Los requerimientos normativos o principios, para poder constituir razones normativas, tienen también que ser (a) generales en el sentido de caracterizar las situaciones a las que se aplican mediante propiedades, o derivar de algún otro requerimiento que satisfaga esa condición; (b) universales, lo que significa que si el principio o requerimiento es aceptado para evaluar una cierta acción en una cierta situación tiene que ser aceptado para evaluar otra acción semejante en situaciones semejantes, lo que notoriamente es una consecuencia de (a). En sentido estricto, la universalidad no apunta a un rasgo del requerimiento sino expresa la exigencia de su uso consistente. (c) Sobreviniencia: la distinción entre situaciones genéricas tiene que recurrir a propiedades empíricas, lo que implica que la "validez" tiene que considerarse sobreviniente a definidas características de este tipo. Por último, (d) integración: pueden existir diferentes clases de razones normativas, pero son mutuamente conmensurables y se ordenan jerárquicamente. Esto quiere decir que las que se ubican en un nivel inferior son derrotadas en caso de conflicto con las de un nivel superior (Nino 1984, pp. 494-495). Habría que observar que (d) no indica, en verdad, un rasgo de las razones, sino más bien describe el postulado filosófico asumido por Nino: la unidad o no fragmentación del dominio de la práctica. Por convención, dice Nino, las razones superiores en la jerarquía son denominadas "morales". Pero lo que Nino no indica en esa lista, en el artículo citado, tal vez por considerarlo obvio, es la propiedad que -según su propia concepción- es la esencial que deben satisfacer semejantes principios o requerimientos para constituir razones normativas: tienen que ser principios, normas o requerimientos válidos, esto es, tienen que estar dotados de fuerza obligatoria. Al menos, ello vale -sin duda alguna-para los requerimientos morales. Los jurídicos - de acuerdo con Nino- carecen de fuerza obligatoria en forma autónoma.

\section{Principios morales}

1. Como se dijo, como los principios o normas morales en la concepción de Nino satisfacen todas esas propiedades, tales requerimientos son razones justificatorias u objetivas, sin discusión. Pero ¿qué es, exactamente, un "principio moral"? Sorprendentemente, mientras es el caso que distingue cuidadosamente varios sentidos de la expresión "norma jurídica", parece que asume la idea de lo que es un 
principio de esa clase como si fuera una noción que carece de ambigüedades. Sin embargo, no es una tarea fácil elucidar esa noción y, de hecho, Nino la utiliza en diversos contextos con distintos sentidos a los que hay que aclarar para identificar a las genuinas razones justificatorias. Por lo pronto, habida cuenta que se trata del significado de expresiones normativas, tiene un cierto contenido proposicional. Nino no indica expresamente cual es. Sin embargo, creo que se puede acordar que se trata de la calificación normativa de acciones. Ciertas conductas están prohibidas, o permitidas, o son obligatorias moralmente, de acuerdo al contenido de esos requerimientos. Un contenido que puede denominarse normativo (Alchourrón y Bulygin 1971, cap. 1). Se podría acordar que la discusión en la práctica moral tiene que versar, precisamente, acerca de la cuestión de saber cuáles son esas conductas o, lo que es lo mismo, cuáles son esos contenidos que hay que calificar como morales.

2. Veamos las alternativas. Correctamente, a mi criterio, Nino sostiene que no existen contenidos específicos que puedan calificarse de "jurídicos". Ello significa que las normas jurídicas no se pueden identificar por las acciones que se califican normativamente (Nino 2013, p. 161). Pero parece inferir una conclusión por descarte, según la cual todos los contenidos normativos son morales (Nino 2013, p. 162). ${ }^{21}$ Esto no puede ser correcto, si se acuerda, por ejemplo, que una formulación normativa según la cual "se debe aniquilar a la población P" no cuenta como principio moral, aunque pueda constituir el contenido perverso de una norma jurídica, de manera que su uso, en ningún caso, puede ser el uso de un principio moral. En una segunda alternativa, se caracterizan en forma negativa: se excluyen como contenidos morales aquellos dirigidos a promover el autointerés de quién los formula, sanciona o impone, i.e. "se debe satisfacer los deseos de x", propuesto, aceptado o impuesto por x, no expresa de manera alguna un principio o norma moral. Precisamente, los deseos marcan la diferencia -para Nino- entre razones morales y prudenciales. ${ }^{22}$ Pero la mera exclusión en este sentido no parece suficiente:

21 Como se verá, una manera de caracterizar a las "normas jurídicas" es decir que se trata de "normas morales", usadas o formuladas en ciertos contextos y por ciertos individuos: las autoridades normativas (Nino 1981, Nino 2013, p. 162).

${ }^{22}$ Parece que, caracterizados de esta manera, los principios normativos de carácter prudencial tendrían que considerarse juicios indexicales. Por ello, no podrían funcionar como enunciados generales y por, lo tanto, no satisfacen una de las condiciones indicadas arriba. Sin embargo, a la inversa de lo que sostiene con relación a las normas jurídicas, considera que expresan razones justificatorias, aunque sean intrínsecamente derrotables (Nino 2014, p. 82 y ss.). 
siempre existe la posibilidad de contenidos perversos que no se relacionan de manera alguna con el autointerés.

3. Por la misma razón, no puede ser admisible, en la propia concepción de Nino, una tercera alternativa según la cual son morales los principios que se aceptan por su contenido. Una idea que Nino utiliza para mostrar que, en última instancia, los jueces justifican sus decisiones en la moral. No solo porque es posible mostrar casos en los cuales los jueces aceptan normas inmorales o perversas sino, además, porque el contenido de una moral objetiva no podría depender de las contingentes actitudes individuales. ${ }^{23}$ En una cuarta opción, se presenta otra idea implausible en el mismo sentido, a saber, que son morales, por convención, aquellos principios de comportamiento que son aceptados como razones últimas en los razonamientos prácticos (Nino 1984, p. 501, Nino 2014, p. 62). De nuevo, ello convierte al contenido de la moral en un dato dependiente de circunstancias empíricas: depende de cuáles son las razones que, de hecho, se consideran últimas por ciertos individuos y en ciertos contextos. Parece que una concepción objetivista o no relativista de la moral y, consiguientemente, del razonamiento práctico correcto como lo es la que cabe adjudicar a Nino, debería presentar exactamente la relación inversa: son últimas en la jerarquía precisamente las razones morales, las que entonces tendrían que ser identificadas con un criterio independiente de cualquier práctica de justificación. ${ }^{24}$ Incluso podría sostenerse que

${ }^{23}$ Como se sabe, gran parte de la jerarquía nazi, incluyendo a los jueces, aceptó la corrección de las normas del derecho nazi, incluso al margen o en contra del propio interés.

${ }^{24}$ Esto es lo que dice expresamente en Nino (1986, p. 75): "el orden moral es independiente de las prácticas de justificación”. A pesar de ello, es realmente problemático determinar cuál es, en definitiva, la concepción general que subyace al pensamiento de Nino. Porque su discusión en el dominio de estas cuestiones, se sustenta explícitamente en una reconstrucción de la práctica moral y de justificación del mundo moderno, determinado por las ideas básicas de la Ilustración. En este sentido, parece que habría que admitir que se trata de una concepción relativista de la estructura, funciones y contenido de la moral, como lo indica Bernard Williams con respecto a la propia idea de "moral" si no se la diferencia de la "ética" (Williams, 1993). No se trataría, entonces, de una propuesta universalista. El mismo Nino señala que, en otros contextos culturales, las razones últimas podrían estar constituidas por razones religiosas o por los mandatos de una entidad sobrenatural (Nino, 2014, p. 84). Pero creo que entenderlo de esta manera constituye un error. No tengo dudas de que, para Nino, la concepción ilustrada de la práctica moral y de sus contenidos (incluyendo a su aparato conceptual), que se propone reconstruir, es la concepción objetivamente correcta, cualquiera que sea su origen histórico. De otra manera sería muy difícil predicar la consistencia de su concepción general. 
semejante independencia resulta de la misma práctica moral. Los principios morales, entonces, tendrían que ser aquellos que deben ser aceptados, como razones últimas, y no los que de hecho se aceptan. Lo más que podría decirse es que los participantes en semejantes prácticas creen que ciertos principios son moralmente correctos, y ese dato explica por qué los consideran razones últimas. Parece claro, entonces, que corresponde adoptar una última alternativa según la cual principios morales son aquellos cuyos contenidos normativos son objetivamente correctos o, para evitar cierta circularidad, podrá decirse que son los que integran la moral objetiva o ilustrada. No encuentro otra manera de caracterizarlos, para explicar por qué son objetivamente válidos y por qué son últimos en cualquier razonamiento práctico correcto: esto es, porque no se requiere de otras normas para justificar su validez. Por lo tanto, solo si se los entiende en este sentido, los principios morales pueden constituir razones justificatorias u objetivas. En lo que sigue voy a asumir, para la discusión, que para Nino es esencial este último concepto de "principio o requerimiento moral", esto es, el que hay que tomar en cuenta al preguntarse por las razones morales para obedecer al derecho.

\section{Normas jurídicas}

1. Hay que analizar, ahora, por qué Nino niega el internalismo jurídico y, por lo tanto, hay que recurrir a la moral en cualquier intento de dar cuenta de la dimensión justificatoria de la práctica jurídica. Por el contrario, Nino admite que para identificar el contenido del derecho es suficiente un concepto descriptivo. En verdad, lo que Nino se propone mostrar, con respecto a normas jurídicas identificadas con un concepto de esa clase, es la tesis negativa según la cual en ningún supuesto pueden constituir razones normativas u objetivas. Esto es importante porque de su eventual fracaso en ese sentido, no se sigue, como es obvio, la tesis positiva de acuerdo con la cual realmente las normas jurídicas puedan constituir semejantes razones. Se puede presentar su argumento en una cierta secuencia.

2. En primer lugar, se descartan como opciones aptas para dar cuenta de la posibilidad de justificación de acciones o decisiones, aquellas nociones de "norma jurídica" que las identifican con prácticas, actos o meros textos sin interpretar. Porque en tal caso, a su respecto solo serían posibles descripciones de hechos (o "proposiciones normativas" como las denomina) y no podrían lógicamente sustentar juicios de deber como los que integran los resultados de las decisiones judiciales. Por supuesto, 
habría que acordar sin dudas con esta exclusión, si se acepta el principio de Hume, como lo anuncia Nino (Nino 1984, p. 493). Por lo tanto, para dar cuenta de esa dimensión hay que identificar a las normas jurídicas con juicios de deber específicos, es decir, con ciertos contenidos normativos, en el sentido indicado arriba. Porque esta es la única manera en que podrían figurar en inferencias lógicamente válidas. El problema es que no existen contenidos específicamente jurídicos. Por consiguiente, dice Nino, "jurídicos" solo pueden ser aquellos contenidos morales que se distinguen -de acuerdo con un concepto descriptivo de derecho- por las circunstancias "de su formulación" (Nino 2013, p. 162) o, si se quiere, de ciertas circunstancias empíricas, por ejemplo, una cierta práctica de uso de esos contenidos. Sin embargo, aquí cabe una primera objeción: como ya fue indicado arriba, no cualquier contenido normativo puede constituir un contenido moral correcto. Por lo tanto, no es suficiente decir que objetivamente los jueces solo tienen disponibles contenidos morales para justificar sus decisiones porque no existen contenidos jurídicos, para concluir que, entonces, necesariamente recurren a la moral. Porque si los contenidos normativos incorporados al derecho son moralmente perversos, no hay manera de admitir que las decisiones de los jueces, en tal caso, se justifican en la moral. Por consiguiente, no puede ser verdad que todas las decisiones de los jueces se justifican en la moral, simplemente porque no existen contenidos jurídicos. Por lo demás, tampoco parece admisible decir que no existe un criterio para determinar la noción de "contenido jurídico". En realidad, la propuesta de una noción semejante -como el mismo Nino lo reconoce al mencionar las "circunstancias de su formulación"- no es especialmente difícil: se puede sostener con plausibilidad que todos los contenidos normativos que satisfacen un criterio empírico de pertenencia $a$ un cierto derecho existente -es decir, un concepto descriptivo- son "jurídicos", independientemente de si, además, constituyen contenidos morales correctos. Una coincidencia que, por cierto, no puede ser necesaria. Como se suele decir, las normas serían de este modo jurídicas con prescindencia de sus contenidos. Si no fuera así, es decir, si se aceptara que todos los contenidos normativos -y no solo los correctos- son "morales", la tesis de Nino sería simplemente trivial: no habría manera de justificar una acción sin recurrir a un principio moral. Creo, no obstante, que ese fiat definitorio permea en cierta manera los otras consideraciones negativas a las que recurre Nino.

3. Básicamente, se trata de presentar la cuestión desde el punto de vista interno, asumiendo la perspectiva de un juez aceptante. Así, Nino 
propone un modelo simplificado de su razonamiento práctico, esto es, el que conduce a sustentar su decisión:

(a) Norma jurídica general $\mathrm{N}$ : "Los locatarios deben pagar el alquiler".

(b) Enunciado sobre los hechos: "x es un locatario".

(c) Norma jurídica particular (sentencia) S: "x debe pagar el alquiler".

Es notorio que aquí la conclusión (c) se deriva lógicamente de las premisas (a) y (b), y si es verdad que (a) expresa una norma jurídica, este modelo representa la idea estándar de "justificación jurídica". No son necesarias premisas adicionales ( $c f$. Moreso, Navarro y Redondo, 1992). Pero para ello, es preciso que $\mathrm{N}$ constituya, además, una razón justificatoria u objetiva autónoma. Esta no es ya una cuestión meramente lógica sino sustantiva, a la que Nino suministra una respuesta negativa: $\mathrm{N}$ carece, así presentada, de la capacidad de funcionar en la dimensión justificatoria. En alguna oportunidad, dice que ello es así porque vendría a carecer de los rasgos que hay que atribuir a semejantes razones. En especial, no le podría atribuir "autonomía", es decir, no es válida en forma directa. Pero ello depende, en realidad, de las razones que se usen para aceptarla.

4. En la primera opción, el juez en cuestión acepta N porque se justifica en otras normas, v.g. una constitución C. Pero para justificar $\mathrm{C}$ hay que recurrir a ulteriores normas, las que finalmente tendrán carácter extrajurídico, v.g la que expresa el deber de obedecer una constitución democrática, la que para Nino es un principio moral sin discusión. En este supuesto, dice Nino, la premisa (a) no es una norma jurídica, aunque tenga el mismo contenido, sino, más bien, un juicio de adhesión normativa. ${ }^{25}$ En definitiva, $\mathrm{N}$ se presenta como una norma moral derivada que constituye la razón justificatoria jurídica -par excellence, dice Nino- y el razonamiento jurídico así presentado

${ }^{25}$ Se trata, a mi criterio, de una tesis muy extraña que defiende en forma reiterada: si N es una "norma jurídica" porque satisface un criterio de identificación, no se ve cómo puede perder esa condición porque un juez adhiera a su contenido, pues en cualquier caso se trata de un circunstancia externa y contingente (en el mismo sentido, Moreso, Navarro y Redondo 1992). ¿Habría que suponer que para los no aceptantes -los que no se adhieren a su contenido- conserva esa condición? Creo que Nino quería decir, con acierto, que para los aceptantes $\mathrm{N}$ representa una razón objetiva que justifica su decisión (Nino 1984, p. 501). Pero para ello no es necesario negar su carácter jurídico. 
tiene que considerarse una especie de razonamiento moral (Nino 1984, pp. 499-500).

5. En la segunda opción, el juez acepta $\mathrm{N}$ directamente porque acuerda que su contenido es correcto, lo que significa para Nino moralmente correcto, es decir, considera que $\mathrm{N}$ es una norma o principio moral al que, en tal caso, hay que atribuirle todas las propiedades de un juicio moral. Tiene los rasgos, entonces, de un razonamiento moral ordinario. Se trata aquí de una presentación con la que es difícil acordar: ¿significa que la aceptación de normas jurídicas por su contenido es suficiente para atribuirle todas las propiedades de una razón objetiva, las que se niegan de toda norma jurídica no aceptada? Si la respuesta es positiva, entonces bastaría la existencia de aceptantes para que el derecho funcione como un dominio de razones justificatorias. Esta, por supuesto, no puede ser la tesis de Nino. Parece que habría que concluir que, en tales supuestos, los jueces creen que las normas que aceptan son efectivamente juicios morales, es decir que, entonces, lo único que se puede hacer es adjudicarles a semejantes creencias la condición de razones subjetivas.

6. Ello muestra en cierto modo la debilidad de un argumento que solo se apoye en una reconstrucción del razonamiento de los aceptantes, aun cuando se admita que la misma es sustancialmente aceptable. Puede ser falso que las normas jurídicas se justifican en normas extrajurídicas de carácter moral aunque los jueces crean en la existencia de normas semejantes, como puede ser falso que los contenidos que aceptan directamente constituyan contenidos morales, i.e. razones objetivas o justificatorias. $\mathrm{O}$ en otras palabras, puede ser falso que las normas que aceptan justifiquen objetivamente sus decisiones. Lo cual implica que semejante argumento parece insuficiente para mostrar que el derecho se vincule objetivamente con la moral en la dimensión justificatoria. Tampoco es suficiente recurrir a los aceptantes así caracterizados para probar que las normas jurídicas no pueden funcionar como razones justificatorias. Porque, como es obvio, los jueces pueden creer, también falsamente, que semejantes normas no son razones justificatorias.

7. En verdad, el recurso a una supuesta reconstrucción del razonamiento judicial y sostener a la vez que los jueces razonan correctamente en ambas alternativas presupone lo que hay que demostrar: a saber, que las normas jurídicas no son ni pueden ser razones objetivas. Lo que se muestra cuando se descarta $a b$ initio el caso de un juez que acepta las normas que se dispone a aplicar porque son jurídicas, 
con prescindencia de cualquier consideración de naturaleza moral, de manera que las considera jurídicamente correctas y, por lo tanto, razones que justifican jurídicamente su decisión. Nino rechaza esta alternativa porque sería lógicamente defectuosa: no habría forma de independizar esas normas de las "circunstancias de su formulación", y la descripción de hechos no pueden constituir razones justificatorias (Nino 2014, pp. 6263, Nino 2013, pp. 162-163). Pero esta idea implica un cierto equívoco: esos hechos solo son criterios de identificación y no integran, como tampoco su descripción, el razonamiento justificatorio del juez. Su punto de partida son los juicios con contenidos normativos identificados con esos criterios. Los jueces que usan un razonamiento de esta clase cometen un error solo si sus creencias son falsas, esto es, si es falso que las normas jurídicas son razones justificatorias objetivas. De la misma manera que cometen un error los que creen que el derecho depende de la moral, si es que semejante creencia también es falsa.

8. El argumento central de Nino para avalar su tesis negativa acerca de las normas jurídicas no puede ser, entonces, la existencia de creencias, i.e. de razones subjetivas, sino más bien es preciso defender el caso en el cual semejantes creencias son verdaderas: ello es así si es verdad que el dominio de las razones objetivas constituye un ámbito unificado y que la moral objetiva representa la instancia última de justificación. No puede haber, en tal caso, razones justificatorias concluyentes inconsistentes con razones morales. Como se dijo, ello no implica la inexistencia de razones de distinta clase, v.g. razones prudenciales (Nino 2014, pp. 82 y ss.) las que, sin embargo, pierden su fuerza justificatoria si existe un conflicto con la moral. Esto es lo que significa decir que son últimas ${ }^{26}$. La defensa de esta concepción no puede ser empírica sino más bien conceptual o filosófica acerca de la mejor manera de pensar el dominio de la práctica. No hay duda de que la concepción del dominio unificado asegura un ideal más básico asociado con la noción de racionalidad, según la cual todas las acciones posibles son o bien racionales, o bien irracionales, para lo cual es preciso contar con un método de decisión. Si todos los dominios fueran inconmensurables, no habría manera racional de

${ }^{26}$ Aunque no puedo discutir aquí este problema, ya que excede el propósito de este trabajo, es interesante advertir que se puede sostener que hay al menos una razón prudencial, es decir, que se sustenta en el autointerés, que es última en cualquier cálculo racional: la que se expresa en el juicio normativo, "debo conservar mi sobrevivencia". Se trata de la clase de razones que podría invocar una versión hobbesiana de la obligación general de obedecer el derecho. 
resolver conflictos de razones y, por lo tanto, ese ideal no podría ser satisfecho. El relativismo en la justificación tiene, por ello, una falla insalvable. $\mathrm{O}$, desde otro punto de vista, si se presupone que las razones son objetivas, no puede haber tampoco conflicto de razones: si objetivamente se debe hacer $\mathrm{A}$, no puede ser verdad que objetivamente se debe hacer no A porque ello equivaldría en cierto sentido a reconocer que el mundo es inconsistente, lo que parece absurdo (si con "objetividad" se apunta a un dato del mundo). Creo que argumentos de esta clase, conjuntamente con su tesis según la cual los requerimientos normativos requieren de otras normas para su validez, i.e. para constituir razones (la idea de "normatividad" justificada), son los que mejor sustentan la postulada dependencia del derecho con la moral.

9. Sin embargo, de la unidad del razonamiento práctico no se sigue que, en ningún caso, las normas jurídicas puedan constituir razones justificatorias, aunque fueran derrotables, como es el supuesto de las razones prudenciales. Es necesario otro paso. El argumento es aquí que, habida cuenta de que todas las normas jurídicas que son aptas para justificar acciones o decisiones, o bien se justifican a su vez en la moral, o bien son directamente normas morales, todas expresan razones morales. No sucede lo mismo con el ámbito de las razones prudenciales, las que, precisamente, se definen así porque no son morales. Pero ¿de qué manera se relaciona el derecho con la moral? Se tienen dos formas, en realidad incompatibles una con la otra, en las que el derecho puede depender de la moral.

(1) En la primera, esta dependencia resulta porque la norma última que concede una autorización al primer legislador jurídico para emitir requerimientos de conducta, necesariamente es una norma moral. Porque la norma última solo puede ser válida por su contenido y no existen contenidos específicamente jurídicos. Este es el supuesto, si la moral incluye, por ejemplo, un principio cuyo contenido impone la obligación de obedecer al legislador democrático. Esta forma satisface la jerarquía entre normas y se corresponde con el primer modelo de razonamiento que Nino atribuye a un juez aceptante. Pero aquí no se ve por qué el derecho no puede representar un ámbito de razones justificatorias, aunque sea prima facie, como se admite en relación al ámbito de las razones prudenciales. De hecho, habría que decir que precisamente esa autorización moral es la que permite, a la autoridad normativa justificada, constituir razones justificatorias previamente inexistentes, a las que se puede denominar "jurídicas". Denominarlas "morales" parece depender de una elección del lenguaje. Es importante indicar que los requerimientos así constituidos por la autoridad legítima serían válidos independientemente de su 
contenido, lo que no parece compatible con la idea de principio o norma moral. Esto tendrá su importancia en lo que sigue.

(2) En la segunda forma, el derecho depende de la moral en la dimensión justificatoria, porque las normas jurídicas solo serían razones objetivas si, y solo si, sus contenidos coinciden con requerimientos morales. Es decir, si son redundantes con respecto a los contenidos de la moral. Si este es el supuesto, correspondiente al segundo modelo de un juez aceptante, entonces es verdad que no puede concebirse un ámbito de razones distinto de las razones morales. Pero aquí no hay cuestión de jerarquía entre normas morales, sencillamente porque no existen legisladores morales. $\mathrm{Ni}$ tampoco puede existir un legislador jurídico legítimo y la norma general de obediencia sería superflua, toda vez que los requerimientos morales son, por definición, intrínsecamente obligatorios. O si se quiere, la autoridad normativa sería intermitente: sus directivas solo serían obligatorias si reproducen requerimientos morales. Lo que se sigue del "imperialismo" que hay que atribuir a la moral en la dimensión justificatoria según la cual todas las acciones posibles están sujetas a una evaluación moral, jerárquicamente privilegiada. ${ }^{27}$

\section{La irrelevancia moral del derecho}

1. Ambos modelos son, en verdad, alternativas excluyentes para representar la dependencia del derecho de la moral. Mientras que (1) conserva para el derecho un ámbito en el que sería posible constituir razones normativas inéditas, (2) se define, en cambio, por el rechazo de esa posibilidad. Lo que se sigue -vale la pena insistir- del carácter objetivo que hay que atribuir a semejantes razones. La irrelevancia moral del derecho parece una conclusión necesaria si se elige (2) porque no hay manera en la que el derecho pueda alterar la calificación normativa de conducta alguna, la que solamente puede ser -en esta perspectiva- una calificación moral. Es interesante advertir que el derecho es también moralmente irrelevante si se admite la versión relativista de la justificación, que supone el internalismo jurídico, esto es, si las decisiones judiciales podrían justificarse en el derecho con independencia de la moral. ${ }^{28}$

27 Dice Nino: "Lo que se trató de defender [...] es que el discurso moral de la modernidad tiene un carácter imperialista que impide la subsistencia de discursos justificatorios insulares" (Nino 2014, p. 82, la cursiva es del autor).

${ }^{28}$ Por supuesto, para el escepticismo acerca de la existencia de razones objetivas, el derecho es también moralmente irrelevante. 
2. Pero es un genuino problema para los que sostienen -como Nino- el carácter unificado del dominio de la práctica. Porque en este supuesto, la irrelevancia moral del derecho implica la irrelevancia práctica del derecho, i.e. es completamente inútil para justificar acciones o decisiones. $\mathrm{O}$, dicho de otra manera, la existencia del derecho no hace ninguna diferencia a la hora de elegir racionalmente entre acciones que se excluyen recíprocamente. A la inversa, como dice Nino: "Si no hubiera un orden moral independiente del derecho este no sería superfluo para la configuración de razones para actuar" (Nino 1986, p. 75). Pero el caso es que existe un "orden moral independiente" y por lo tanto es una paradoja admitir la propia existencia del derecho como si fuera otro orden normativo.

3. Como ya se dijo, en su artículo "La paradoja de la irrelevancia moral del gobierno y el valor epistemológico de la democracia" (Nino 1986a), Nino presenta este problema desde el punto de vista de otra cuestión, la de saber si es posible o no justificar la democracia -cabe entender-como única forma de gobierno legítimo. Justificar moralmente el gobierno es equivalente a justificar moralmente su autoridad normativa, es decir, su capacidad moral para promulgar normas de comportamiento.

Semejante programa es sumamente complejo, y voy a limitarme aquí a formular alguna observación. Porque la condición de justificación de la democracia que propone Nino supone que hay que justificar la alternativa (1) con respecto a la relación entre moral y derecho, i.e. la existencia de un principio moral según el cual se debe obedecer a la autoridad democrática en forma general, esto es, con independencia del contenido de las normas promulgadas. ${ }^{29}$ Pero para presentar la existencia de lo que denomina "paradoja de la irrelevancia moral del gobierno" presupone la verdad de la alternativa (2) con respecto a la relación entre moral y derecho. Esta cuestión se puede presentar también bajo la forma del dilema de Eutifrón, suscitado cuando se interroga acerca de la autoridad moral de Dios, la que, por cierto, se extiende a cualquier autoridad legítima a la que se asocia la obligación general de obediencia. Así, dado el supuesto de la existencia de esta obligación, se tienen, de nuevo, dos alternativas:

(3) Los requerimientos de conducta que emite una autoridad legítima son válidos porque los emite una autoridad legítima.

${ }^{29}$ Una alternativa - recuérdese - que para Nino es la que conduce a una forma de razonamiento específicamente jurídico (Nino 1984, p. 500). 
O bien,

(4) La autoridad legítima emite esos requerimientos porque son válidos.

4. Según (3) la autoridad legítima constituye el dominio moral. Según (4) el dominio moral es objetivamente independiente. Pero a la hora de preguntarse si hay, o no, que obedecer a Dios, la respuesta positiva es ineludible: dado que Dios es infinitamente bueno e infalible, se debe obedecer a Dios en cualquier caso. No hay cuestión con relación a la existencia de la obligación general de obediencia a Dios. ¿Cómo se extrapola este dilema al espacio de las autoridades empíricas, bajo el obvio supuesto según el cual todas las autoridades democráticas son empíricas? La cuestión es esencial porque para conservar la legitimidad de una autoridad hay que probar (3) o bien probar (4). Si ambas proposiciones son falsas, no existe ninguna obligación general y, por lo tanto, no existe ninguna autoridad legítima de índole empírica, si se la entiende de esta manera.

5. Como Nino admite que existe un orden moral independiente del gobierno, de lo que resulta su irrelevancia moral, es decir, admite (2) con respecto a la relación entre moral y derecho, el itinerario de su argumento, aunque no lo indique de esa manera, tiene que dirigirse a sustentar alguna forma de (4). Para ello, Nino revisa y descarta, a mi juicio con razón, una serie de propuestas para conservar la relevancia moral del derecho, todas las cuales serían intentos de probar alguna forma de (3), lo que es imposible si el derecho no puede ser constitutivo de la moral. En especial, descarta, en ese sentido, la idea de que la discusión moral que culmina en un consenso acerca de los principios que hay que considerar válidos pueda servir para constituir la validez de los principios acordados. Si fuera así, esto podría servir como primer paso para justificar la democracia como forma de gobierno habida cuenta de que uno de los atributos que hay que adjudicarle es la deliberación racional y pública acerca de los contenidos del derecho. Siempre bajo el supuesto según el cual esos contenidos, si se justifican, tienen en todo caso carácter moral, la descarta porque semejante discusión es, en realidad, un proceso cognoscitivo acerca de la cuestión de saber cuáles son esos principios morales válidos (Nino 1986a, pp. 78-79). Para Nino, como se sabe, el criterio de validez depende de un condicional contrafáctico: válidos son aquellos que se aceptarían en ciertas condiciones ideales de "imparcialidad, racionalidad y conocimiento 
plenos" (Nino 1986a, p. 78), las que no se pueden reproducir en las discusiones empíricas. ${ }^{30}$

6. No obstante no es posible sostener, entonces, la relevancia moral del derecho recurriendo a una inexistente capacidad de generar razones objetivas, Nino dice que lo hay que poner en cuestión es la posibilidad de un acceso a la verdad moral con independencia de la discusión moral. ${ }^{31}$ Así, dice Nino:

El discurso o discusión moral es la práctica social dirigida a obtener consenso unánime acerca de ciertos principios que sirven de justificación última de acciones e instituciones (Nino 1986a, p. 77).

Por consiguiente, para mantener aquella relevancia, el gobierno encargado de la producción de normas jurídicas debería adoptar la forma que reproduzca al máximo las condiciones de una práctica moral, bajo la exigencia ineludible según la cual su objetivo tiene que ser la búsqueda de la verdad moral. Una condición que se presenta asimismo como una característica ideal, pero posible de una autoridad normativa. La democracia se define, precisamente, porque los resultados normativos del gobierno dependen de una deliberación previa acerca de las razones a favor y en contra de las medidas a adoptar. Por ello, dice Nino:

La democracia tiene valor epistemológico como un método adecuado de conocimiento moral ya que ella incluye esencialmente la discusión $\mathrm{y}$ el acuerdo mayoritario, que son formas de aproximarse a la verdad moral (Nino 1986a, p.81).

${ }^{30}$ No está muy claro si, para Nino, el consenso ideal sería constitutivo de la moral objetiva, esto es, de la propiedad "validez". Ello porque aunque denomina a su propuesta metaética "constructivismo epistemológico", no se ofrece un criterio independiente de ese acuerdo para dar cuenta de su dimensión ontológica. Reproduce así el dilema de Eutifrón. Efectivamente, no le parece a Nino un equívoco razonar acerca de la identidad de los principios morales suponiendo cuales habrían sido los que Dios hubiera promulgado si existiese (Nino, 1986b, p.108). Sin embargo, la discusión acerca de la concepción metaética de Nino excede el propósito de este trabajo.

${ }^{31}$ No tenemos, dice Nino, un "conocimiento moral independiente" de la práctica discursiva (Nino 1986a). No está claro si ello quiere decir que la discusión moral es una condición necesaria para alcanzar la verdad moral o si se trata de una forma epistémica privilegiada. Tampoco puedo discutir aquí esta cuestión. 
7. Es preciso tener presente, sin embargo, el alcance de su argumento aquí para evitar alguna confusión. La práctica de la discusión moral que existe de hecho, y que culmina en un consenso, solo puede ser un intento de reproducción de las condiciones de un consenso ideal. ${ }^{32}$ Por lo tanto, el consenso en cuestión solo puede ser una "representación prima facie fiel de ese consenso ideal". A su vez, la democracia representativa, que adopta el principio de la mayoría y no requiere el consenso, i.e. la unanimidad, solo puede ser por ello un sucedáneo imperfecto de una discusión moral en sentido estricto. Creo, además, que hay que dar un paso más en el pensamiento de Nino: no cualquier proceso democrático empírico puede asumirse como un sucedáneo de una discusión moral. Solo sería admisible adjudicarle ese carácter a aquellos no permeados por la ideología de grupos de presión, por intereses partidarios de la mayoría o por cualquier otro factor que pueda distorsionar la búsqueda de la verdad moral. De manera que, de nuevo, semejantes procesos democráticos tienen que ser pensados a su vez como aproximaciones a un modelo ideal de democracia, esto es, como aproximaciones a un sucedáneo genuino de la discusión moral. Por ello, el recurso a la discusión como criterio epistemológico solo puede ser gradual y su fuerza de convicción tiene que depender de su relativa aproximación al consenso ideal en el que se alcanza la verdad moral. Más acá de ese estadio, todos los resultados son falibles y solo se les puede adjudicar en diferentes grados una presunción de verdad moral y, por lo tanto, las normas así emitidas, solo pueden considerarse presuntivamente válidas. Es decir, presuntivamente obligatorias. Nino, por supuesto, se hace cargo de todos estos límites epistémicos, pero la democracia es siempre mejor que cualquier otra forma de gobierno, precisamente porque la discusión -aun distorsionada- la integra de manera esencial.

8. Se puede acordar con esta defensa de la democracia. Pero ¿es suficiente para probar la existencia de una obligación moral general de obedecer el derecho de una democracia? Semejante obligación es necesaria para admitir que las decisiones de los jueces se justifican en todo caso en razones morales. Habida cuenta de que, en la propia concepción de Nino, las decisiones democráticas no son infalibles, a la inversa de lo que ocurre con las decisiones de Dios o en el estado ideal de consenso, la respuesta

${ }^{32}$ La discusión conjunta es necesaria para tener en cuenta los intereses de todos los afectados por la decisión que habrá de tener consenso. Se trata, en verdad, de una controversia acerca de cuáles son los intereses dignos de ser defendidos (Nino 1986a, p. 80). 
debería ser negativa. Pero Nino sostiene que, en ausencia de una razón en contra, se debe moralmente cumplir con las prescripciones de una autoridad democrática. Así culmina su ensayo con el dictum según el cual:

En proporcionarnos esas razones [para la creencia] reside la superioridad moral de la democracia, ya que tenemos razones para hacer aquello que tenemos razones para creer que tenemos razones para hacer (Nino 1986a, p. 82).

Para comprenderlo, se puede suponer que los individuos que componen una autoridad democrática promulgan la norma $\mathrm{N}=$ "Se debe hacer p". Se puede suponer, además, que esos individuos creen sinceramente que, de acuerdo con la moral, efectivamente se debe hacer $p$. De manera que, en tal caso, las razones para creer que se debe hacer p están constituidos, a su vez, por una creencia. Se tienen, entonces, dos versiones posibles del dictum de Nino.

La existencia de esa creencia de la autoridad democrática es una razón para creer en la validez de N, esto es, en la existencia de una razón objetiva para hacer p. Para satisfacer esa razón para creer, hay que creer, entonces, en la existencia de una razón objetiva para hacer p. O, lo que significa lo mismo, hay que adquirir una razón subjetiva para hacer p. En esta lectura, básicamente aceptable, habría que entender que la tesis de Nino dice que hay una razón subjetiva para hacer aquello que se tiene razones para creer que se tienen razones para hacer ${ }^{33}$.Pero ello, obviamente, no es suficiente para probar que efectivamente se debe hacer p, i.e. no es suficiente para probar la validez de N.

9. La segunda versión -la que parece sostener Nino- dice que la existencia de una razón para creer que existe una razón para realizar p, implica la existencia de una razón objetiva para realizar p, esto es, implica la verdad de la creencia. Entendido de esta manera, semejante conclusión es un genuino non sequitur, porque de la misma manera en que no es posible inferir de la creencia de una cierta proposición P la verdad de $\mathrm{P}$, tampoco es posible esa inferencia de una razón para creer en la proposición P. Para evitar esta objeción habría que sostener que, o bien las creencias de los individuos que integran la autoridad democrática son infalibles, o bien que son constitutivas de la verdad moral. Nino

${ }^{33}$ Voy a dejar de lado aquí otra complicación adicional del dictum: seguramente de la existencia de razones para creer en $\mathrm{p}$, no se sigue la existencia de la creencia en $\mathrm{p}$, como supone esta lectura. 
tendría que rechazar ambas opciones porque están excluidas en una concepción objetivista de la moral. Puede ser que, entonces, el valor moral de la democracia no dependa necesariamente de la obligación de obedecer al derecho.

\section{Bibliografía}

Alchourrón, C. (1981), "Razones y prescripciones: Una discusión”, en Análisis Filosófico, I(1), pp. 49-57.

Alchourrón, C. y Bulygin, E. (1971), Normative Systems, Nueva York, Springer.

—_ (1996), "Norma jurídica", en Garzón Valdés, E. y Laporta, F. (eds.), El derecho y la justicia: Enciclopedia Iberoamericana de Filosofía, Madrid, Trotta.

Bayón, J. C. (1991), La normatividad del derecho: Deber jurídico y razones para la acción, Madrid, Centro de Estudios Constitucionales. (1996), "Deber jurídico", en Garzón Valdés, E. y Laporta, F. (eds.), El derecho y la justicia: Enciclopedia Iberoamericana de Filosofía, Madrid, Trotta.

Brink, D. O. (1994), Moral Realism and the Foundations of Ethics, Cambridge, Cambridge University Press.

Farrell, M. (1986), "En busca de la voluntad de Dios", Análisis Filosófico, VI(2), pp. 97-102.

Hart, H. L. A. (1991), The Concept of Law, Oxford, Clarendon Press.

Moreso, J. J., Navarro, P. E. y Redondo, M. C. (1992), "Argumentación jurídica, lógica y decisión judicial”, Doxa: Cuadernos de Filosofía del derecho, 11, pp. 247-262.

Nino, C. S. (1981), "Razones y prescripciones", en Análisis Filosófico, I (1), pp. 37-48.

(1984), "Legal Norms and Reasons for Action", Rechtstheorie 15, pp. 489-502.

(1986a), "La paradoja de la irrelevancia moral del gobierno y el valor epistemológico de la democracia", Análisis Filosófico, VI(2), pp. 65-82.

_ (1986b) "La justificación de la democracia: entre la negación de la justificación y la restricción de la democracia. Réplica a mis críticos", Análisis Filosófico, VI(2), pp. 103-114.

(2007), "Respuesta a J. J. Moreso, P. E. Navarro y M. C. Redondo", en Maurino, G. (ed.), Derecho, moral y política I: Los escritos de Carlos Nino, Buenos Aires, Gedisa.

(2013), Ocho lecciones sobre ética y derecho: Para pensar la 
democracia, Buenos Aires, Siglo XXI.

Nino, C. S. (2014), Derecho, moral y política: Una revisión de la teoría general del derecho, Buenos Aires, Siglo XXI.

Peacocke, C. (1997), "Concepts", en Dancy J. y Sosa E. (eds.), A Companion to Epistemology, Oxford, Blackwell, pp. 74-76.

Quinn, W. (1993), "Putting Rationality in Its Place", en Morality and Action, Cambridge, Cambridge University Press.

Rodríguez Larreta, J. (1986), "Democracia y moral: Respuesta a Nino", Análisis Filosófico, VI(2), pp. 83-95

Williams, B. (1993), Ethics and the Limits of Philosophy, Londres, Fontana Press.

Zimmerman, M. (1996), The Concept of Moral Obligation, Cambridge, Cambridge University Press.

Recibido el 27 de septiembre de 2014; aceptado el 3 de diciembre de 2014. 